\title{
Estudo de caso: Levantamento e análise da realidade de uma cooperativa de Energia Elétrica
}

\author{
Case study: Survey and analysis according to the reality of a cooperative Electricity
}

\begin{abstract}
Resumo
A distribuição de energia elétrica é um serviço público essencial para a população cuja demanda pela prestação está aumentando cada vez mais. É neste sentido, que a pesquisa possui como objetivo geral, identificar os problemas mais comuns na prestação do serviço de distribuição de energia elétrica, bem como ressaltar os fatores que precisam ser melhorados para otimizar a qualidade do serviço prestado pela cooperativa Rio Grande Energia S.A (RGE), unidade de Palmeira das Missões, localizada no interior do estado do Rio Grande do Sul. Quanto ao método, a pesquisa contou com uma pesquisa descritiva qualitativa, aplicada diretamente com os colaboradores da instituição. Os resultados obtidos indicaram que a Estação precisa verificar a qualidade do atendimento telefônico, pois este não está adequado com a legislação vigente. Torna-se necessário que se faça um estudo diante das dificuldades geradas por fatores climáticos de raios e vendavais. Além disso, outro problema identificado e de relevância para o bom desempenho na prestação do serviço caracteriza-se pelo acúmulo de serviços devido ao aumento da demanda associado à falta de pessoal para trabalhar e o tempo de deslocamento para a prestação do serviço.
\end{abstract}

Palavras-chave: Serviço Público. Cooperativa. Energia Elétrica. Gestão. Ações Estratégicas.

\begin{abstract}
The distribution of electricity is an essential public service to the population whose demand for providing is increasing more and more. In this sense, the research has as main objective to identify the most common problems in the provision of electricity distribution services, as well as highlight the factors that need to be improved to optimize the quality of service provided by the cooperative Rio Grande Energia SA ( RGE), Palm unit of the Missions, located in the state of Rio Grande do Sul. As for the method, the study used a qualitative descriptive research, applied directly to the employees of the institution. The results indicated that the station needs to check the quality of telephone service because it is not appropriate to the current legislation. It becomes necessary to make a study on the difficulties caused by climatic factors rays and gales. Also, another problem identified and relevance to the performance in service delivery is characterized by the accumulation of services due to increased demand associated with lack of personnel to work and travel time to the service provided.
\end{abstract}

Keywords: Public Service. Cooperative. Electricity. Management. Strategic Actions.

Recebido: 16/09/2015 Aceito: 16/03/2016

Maristela de Oliveira ${ }^{1}$, Ana Cláudia Santos Silveira Zuliani², Michellini Rozo Brescovit ${ }^{3}$, Shaiane Caroline Kochhann ${ }^{4}$ e Sandra Leonara Obregon ${ }^{5}$.

${ }^{1}$ Universidade Federal de Santa Maria, Graduação em Administração- marioliveira89@ hotmail.com -

Av. Coronel Evaristo, 142, apartamento 203, Bairro Cohab, Palmeira das Missões/RS, CEP 98300-000

2 Universidade Federal de Santa Maria, Graduação em Administração- anazuliani@hotmail.com

${ }^{3}$ Universidade Federal de Santa Maria, Graduação em Administração- miche.brescovit@ gmail.com

${ }^{4}$ Universidade Federal de Santa Maria, Especialização em Gestão Pública Municipal - shaikochhann@ @otmail.com

${ }^{5}$ Universidade Federal de Santa Maria, Graduação em Administração - sandraobregon12@ gmail.com 


\section{Introdução}

$\mathrm{O}$ Fornecimento de energia elétrica é considerado um serviço público essencial para a população. Este é de forma contínua, ininterrupta e adequada, sendo possível por meio dele realizar diversas atividades domésticas e profissionais, obter informações, operar tecnologias, entre outros, sendo a única justificativa para sua interrupção a inadimplência do consumidor (NILSSON, 2012).

De acordo com a Agência Nacional de Energia Elétrica, o Brasil possui 63 concessionárias que prestam o serviço público de maneira cooperada, para a distribuição de energia e um grupo de cooperativas denominadas permissionárias. Tais organizações são regulamentadas pela ANEEL por meio de normativas, as quais determinam alguns princípios para o fornecimento de energia elétrica com qualidade, de maneira atualizada e consolidada (ANEEL, s.d).

Neste contexto, o presente estudo foi motivado pela disparidade na qualidade da prestação do serviço de fornecimento de energia elétrica entre as cooperativas de eletrificação rural e a empresa privatizada. Assim, tem-se como objetivo geral buscar identificar os problemas mais comuns na prestação do serviço de distribuição de energia elétrica, bem como ressaltar os fatores que precisam ser melhorados para otimizar a qualidade do serviço prestado pela empresa Rio Grande Energia S.A (RGE), localizada no município de Palmeira das Missões.

Assim, parte-se da premissa de que a através deste estudo, busca-se realizar uma análise dos problemas diagnosticados sobre a prestação do serviços no modelo de gestão da unidade privatizada da Rio Grande Energia (RGE-Rio Grande Energia S.A). Desta forma, buscou-se estudar mais a fundo a realidade da cooperativa, partindo-se do questionamento: Quais fatores influenciam de maneira negativa e que necessitam ser examinas de forma emergente quanto a prestação do serviço pela RGE? Salienta-se a importância desta pesquisa devido ao grande aumento na demanda por energia elétrica por parte dos consumidores. Segundo o site da Empresa de Pesquisa Energética (EPE) a demanda de energia elétrica no Brasil deve crescer $4,3 \%$ ao ano até 2023. Conforme dados da EPE sobre o consumo de energia elétrica no mês de maio de 2015 no Sul do país, na área residencial o mesmo foi de 1.588.778 Megawatt-hora (MWh), o consumo industrial foi 2.634.144 MWh e o consumo comercial foi de 1.204.091MWh.

Ressalta-se também que não existem muitas pesquisas nas concessionárias de energia, principalmente no que concernem as resoluções normativas da ANEEL-Agência Nacional de Energia Elétrica. Nesse sentido, Malmegrin (2010), afirma que o gestor operacional deve estar preparado para atuar nas ações discricionárias e legais, tendo em mente que existem regras para serem cumpridas em conciliação com a conjuntura econômica que se apresenta em determinada situação.

Os resultados desse trabalho servirão de apoio para a gerência do departamento de serviços de rede Centro da Estação da RGE de Palmeira das Missões, favorecendo uma estratégia para a tomada de decisão, visando melhorar a qualidade dos serviços prestados aos consumidores, levando em consideração as normativas estabelecidas.

\section{Prestação de Serviços Públicos pelas Cooperativas de Energia Elétrica e as Agências Reguladoras - ANEEL}

Tendo em vista a complexidade das funções desempenhadas pelo Estado e a extrema necessidade da prestação de serviços públicos eficientes e de qualidade para o bem estar da população, optou-se pelo processo de descentralização. Dessa forma, o ordenamento jurídico criou as agências reguladoras como entidades independentes com especialização técnica e poder normativo para regulamentar diversos setores da economia em função de trazer benefícios para o interesse público e ampliar o controle destes serviços, bem como sua melhoria (FARINA, 1994).

As agências regulatórias têm papel importante no desenvolvimento dos setores da economia, pois possuem a função de sanar as falhas de mercado. E pelo fato de existir produtos e/ou serviços que não podem ser adequadamente comercializados no mercado, considerados essenciais e não excludentes, as agências regulatórias controlam para que nenhum cidadão seja excluído de usufruir destes serviços (BANCO CENTRAL DO BRASIL, 2013). 
Uma forma de contornar as falhas de mercado é a criação de um sistema de regulação para impor regras econômicas ao serviço público. Assim, acredita-se que a fragmentação das empresas prestadoras de serviços, com a introdução de um número maior de operadores em cada segmento, é suficiente para atrair mais o capital privado, aumentar a concorrência e satisfazer a demanda destes pelos consumidores com qualidade, eficiência e de forma mais barata (LANDI, 2007).

As agências reguladoras prestam-se - ordinariamente para fomentar a regulamentação do mercado, com vistas a impedir o abuso das empresas, com o objetivo de garantir excelência e padrões de qualidade. De modo a realizar seus fins, as agências dispõem de independência de ação, para que possam definir políticas e estratégias setorizadas. (REVISTA DA PROCURADORIA - GERAL DO BANCO CENTRAL, 2013, p. 21).

Corroborando, Fadul (2002, p. 1) afirma que as agências reguladoras nacionais foram criadas "com objetivo de regular, fiscalizar políticas setoriais, estabelecer tarifas, atrair o investidor internacional controlando a entrada e saída de empresas do setor." Além disso, todo esse conjunto tem o propósito de criar um ambiente favorável para a concorrência.

Sendo assim, o setor elétrico criou a Agência Nacional de Energia Elétrica (ANEEL) e nesse mesmo modelo foram criadas agências regulamentadoras em outros setores da infraestrutura, tais como nas telecomunicações, a Agência Nacional de Telecomunicações (ANATEL), na água a Agência Nacional das Águas (ANA), e no petróleo e gás a Agência Nacional de Petróleo, Gás Natural e Biocombustível (ANP) (FADUL, 2002).

Com a chegada da privatização do setor elétrico e por meio da Lei $n^{\circ} 9.427$ de 26 de dezembro de 1996 e regulamentada pelo decreto $\mathrm{n}^{\circ}$ 2.335 de seis de outubro de 1997, a ANEEL surgiu configurando um regime jurídico de autarquia especial, vinculado ao Ministério das Minas e Energia (MME) com sede no Distrito Federal, tendo como função específica regulamentar a geração, distribuição e comercialização de energia elétrica (ANEEL, s.d).

Com a privatização do que antes era subordinado ao monopólio estatal, surgiu à necessidade de regular o setor, com normatizações, estabele- cendo-se regras para a iniciativa privada, com enfoque na qualidade dos serviços, forma de aplicação de tarifas e todos os demais aspectos relacionados à geração, transmissão e distribuição de energia elétrica (GUIMARÃES e SILVA, 2000).

Conforme a Lei de criação, a ANEEL possui diversas competências básicas, sendo as mais relevantes: a fiscalização e regulação dos setores de transmissão, distribuição e fiscalização de energia elétrica em consonância com as políticas federais, execução dessas políticas a fim de explorar os recursos hídricos para geração de energia, celebração de contratos de permissão e concessão de serviços públicos de energia, mediação de desacordos entre as empresas operadoras do setor e seus consumidores. Outro fator importante, é que a principal fonte de receita da ANEEL são os fundos arrecadados com as taxas de cobranças nas fiscalizações dos serviços de energia (GUIMARAES e SILVA, 2000), além disso, o autor Prado (2006, p.5) reforça ao afirmar que "a ANEEL possui autonomia gerencial, financeira e competência para normatizar questões técnicas, assim como autonomia decisória".

Nesse sentido, as agências reguladoras em especial a ANEEL, atuam num ambiente conturbado entre a política e a economia social, sendo que esses focos de pressão podem ser analisados em dois âmbitos dos estudos sobre regulamentação: o primeiro é como se regula, caracterizado pelas análises em relação aos poderes políticos e as agências reguladoras e o segundo é de análise corresponde o lado da demanda, ou seja, o relacionamento da regulação com a sociedade ou com os grupos econômicos do país (SILVA, 2012).

Conforme Queiroz (2010,pg. 16), "a distribuição da energia elétrica é objeto de concessão do serviço público, sendo um dos preceitos deste, o serviço adequado". Desta forma, para a distribuição de energia é visível à necessidade de investimentos em tecnologia e inovação, e como o Estado não conseguia mais realizar os investimentos necessários tanto para modernização quanto para atendimento do consumidor, decidiu-se por decentralizar o poder praticando inúmeras privatizações no setor elétrico.

Ressalta-se que a finalidade da ANEEL é fiscalizar o setor elétrico brasileiro, pois as conces- 
sionárias públicas de distribuição de energia assumem características peculiares na região onde atuam o que é a característica de monopólio natural. Desta forma, ela tem que regular o monopólio para que não ocorra uma concorrência desleal em que uma única empresa detém o mercado de um produto ou serviço e ainda influencia no preço (MACHADO, 2014).

Ademais, conforme as exigências da ANEEL, é necessário ter uma ouvidoria, a qual deve ser bem diversificada nas empresas reguladoras. Essa devem funcionar como uma espécie de filtro para as solicitações realizadas pelos consumidores, sendo uma de suas principais funções o registro de lacunas na regulação e fonte de subsídios de informações para a melhoria do relacionamento do cliente com a concessionária (PRADO, 2006).

\subsection{Distribuição Energética à População}

A distribuição de energia elétrica é um serviço público essencial para a população cuja demanda pela prestação está aumentando cada vez mais. Na região Norte do Rio Grande do Sul as cooperativas de eletrificação rural se destacam na distribuição de energia. Essa dicotomia pode ser explicada no modelo de gestão entre as empresas privatizadas e as cooperativas. Para Pelegrini et. al (2003, p. 2 ) "as cooperativas de eletrificação rural são agentes presentes no setor elétrico desde a década de 40 e expandindo-se mais fortemente nas décadas de 60 e 70."

Ressalta-se que a primeira cooperativa de eletrificação rural no Brasil foi fundada em 1941 no Oitavo distrito de José Bonifácio, hoje cidade de Erechim/RS. Entretanto, no ano de 1968, esta perdeu sua finalidade quando as redes da Companhia Estadual de Energia Elétrica (CEEE) chegaram à região (FECOERGS, s.d).

A partir da reestruturação do setor elétrico brasileiro e perante a legislação vigente, tornouse necessário regularizar essas cooperativas sob a forma de permissionárias ou autorizadas (PELEGRINI et. al, 2003). No estado do Rio Grande do Sul, as cooperativas de eletrificação rural são filiadas a Federação das Cooperativas de Energia, Telefonia e Desenvolvimento Rural do Rio Grande do Sul (FECOERGS) órgão que regulamenta e fiscaliza as cooperativas em seu desem- penho técnico operacional e comercial (FECOERGS s.d).

Além da FECOERGS, o órgão regulamentador ANEEL, também atua nas cooperativas de eletrificação rural. Essas cooperativas possuem uma gestão comunitária composta por associados que se empenham em trabalhar de forma conjunta e eficiente (CRELUZ s.d). Elas se desenvolvem em um modelo de autogestão onde os associados participam das decisões e se reúnem anualmente para avaliar e discutir ações (PRADO, 2002), criando assim um modelo de gestão transparente para seus associados.

No que se refere às empresas estatais Miranda e Amaral (2011, p. 4) afirmam que estas "devem ser pautadas pela responsabilidade para com seus proprietários, os governos e os demais interessados, e a governança corporativa deve ser um instrumento para a consecução de tal objetivo." O estado investe nas estatais por ser motivado pela oportunidade propiciada por estas empresas para sanar as falhas de mercado e também pelas ideologias políticas.

Muitas vezes, a administração das estatais passa por dificuldades, pois o controle governamental destas é efetuado por meio de agências governamentais e ministérios, sendo que a direção dos ministérios e das empresas é dividida entre partidos políticos com interesses diferenciados. Ademais, é o estado o principal proprietário das empresas estatais e a governança corporativa estabelece a transparência em suas ações de negócios e investimentos que pode representar uma estratégia de valor para as mesmas (MIRANDA; AMARAL, 2011).

A privatização do setor elétrico e sua estruturação em um novo modelo fazem parte da transição econômica no país. A distribuição de energia no Brasil era uma atividade estatal, porém demandava de investimentos no setor elétrico e a partir disto a gestão estatal migrou para a privada. A dificuldade para obter recursos a nível nacional e internacional para esses investimentos no setor foram alegações do governo federal para desenvolver e implantar em 1990 o novo modelo concomitantemente com uma privatização (ZILBER; LEX; ADES, 2005). A partir da privatização, passou-se a exigir dos gestores das empresas uma atuação empresarial com objetivos mais estratégicos e uma maior atenção para as novas 
variáveis que surgiam com estas mudanças (ZILBER; LEX; ADES, 2005).

$\mathrm{Na}$ empresa em estudo, os objetivos são determinados com base nas metas estabelecidas pela ANEEL sobre os indicadores de conjunto. Sendo estes conjuntos referentes à Duração Equivalente de Interrupção por Unidade Consumidora (DEC) e Frequência Equivalente de Interrupção por Unidade Consumidora (FEC). Para cada um desses indicadores a estação tem uma meta diferenciada e com base nessas metas são definidas todas as ações a serem realizadas para que fiquem dentro dos indicadores estabelecidos pelo órgão regulador.

A reforma do setor elétrico brasileiro introduziu elementos legais e tecnológicos em sua organização exigindo novos modelos de gestão empresarial com estratégias mais complexas. Dessa forma, para os administradores destas empresas a definição deste modelo de gestão que traduzam em ações estratégicas são elementos importantes no processo da tomada de decisão (FIGUEIREDO, 1999).

Considerando que as ações para o melhoramento do desempenho dependem da prestação de serviço realizada, torna-se necessário manter uma equipe de colaboradores capacitada e motivada para a efetivação deste trabalho. Na estação, foco do estudo, os colaboradores são motivados com base em um plano de avaliação de desempenho anual chamado de "Valor Pessoal", onde são realizadas avaliações individuais de desempenhos e de metas alcançadas. A partir disso, os funcionários podem ser recompensados com bônus financeiros ou aumentos salariais, sendo que esta matriz de desempenho serve também para casos de recrutamento interno de ascensão profissional.

$\mathrm{Na}$ estação, as atividades são coordenadas com base na mão de obra disponível, regras e prazos da resolução 414 e metas definidas previamente sobre os indicadores de desempenho. Os recursos são distribuídos conforme planejamento prévio tendo como base os indicadores realizados em períodos anteriores que indicam onde são necessárias ações pontuais para melhorar o desempenho.

Os novos modelos de gestão e as estratégias competitivas oferecem para as empresas concessionárias uma visão mais ampla e integrada do que uma simples verificação de indicadores (FIGUEIREDO, 1999). Considerando a empresa privatizada em estudo, sua gestão é focada no desempenho do produto, ou seja, a entrega de energia elétrica com qualidade, utilizando sistemas de controle que auxiliem e mostrem as ações necessárias para que o cliente final tenha um produto de qualidade e continuidade, conforme determina a normativa que regula a distribuição de energia.

\subsection{Estação da RGE em Palmeira das Mis- sões/RS}

Na cidade de Palmeira das Missões/RS, a RGE possui uma Estação Avançada desde 2008, a Estação Avançada de serviço de campo - EA1, possui um total de 35 funcionários distribuídos nos setores técnico, administrativo e atendimento de campo sendo que alguns destes funcionários são membros da Comissão Interna de Prevenção de Acidentes (CIPA) na estação.

Esta atende a um contingente de 21 municípios na região, sendo estes: Sarandi, Santo Augusto, Constantina, Palmeira das Missões, São José das Missões, Lajeado do Bugre (área rural), Dois Irmãos das Missões, Boa Vista das Missões (área rural), Novo Barreiro, Barra Funda, Engenho Velho, Liberato Salzano, Nova Boa Vista, Novo Xingu, Ronda Alta, Rondinha e Sagrada Família, São José do Inhacorá, São Valério do Sul, Chiapetta e São Pedro das Missões. Destaca-se que a estação atende aproximadamente 51.000 unidades consumidoras.

Além disso, a estação não possui um Centro de Operação de Distribuição (COD). As equipes são distribuídas pelo COD da cidade de Caxias do Sul, que atende toda a empresa, inclusive monitora os religamentos automáticos. O Call Center está localizado na cidade de Indaiatuba/SP e atende todo o grupo CPFL energia. Para gerenciar o atendimento das reclamações são gerados relatórios diários, semanais e mensais. Logo, por meio das informações destes relatórios são tomadas medidas corretivas nas reclamações.

Para atender uma ocorrência, os plantões são alocados via sistema de rastreamento chamado Nastek e por meio deste o COD visualiza a equipe que está mais próxima da ocorrência gerando uma ordem de serviço para o atendimento da mesma atra- 
vés de uma mensagem de texto para o operador. $\mathrm{O}$ COD sempre prioriza os atendimentos nos tipos de ocorrências que geram risco de vida, como fios caídos, por exemplo, e nestes casos desliga toda a rede para atender a ocorrência.

Ainda, os documentos e as liberações para atender as ocorrências programadas ou não programadas são todos organizados e expedidos pela sede em Caxias do Sul. Na estação de Palmeira das Missões os operadores são responsáveis apenas pela organização dos equipamentos e materiais de trabalho. No momento em que a equipe atende a ocorrência, esta repassa para o COD de Caxias do Sul todos os dados da mesma, bem como a quilometragem do veículo e o tempo de duração do atendimento a ocorrência. As equipes sempre trabalham em dupla, sendo que há uma dupla de plantonistas que ficam de sobreaviso e mais cinco colaboradores que semanalmente fazem plantão caso haja necessidade da troca de postes.

Por fim, é importante ressaltar que os funcionários da estação são treinados constantemente sobre segurança, regulamentação, ISO 9000 e responsabilidade social e ambiental.

\subsection{Metodologia}

Metodologicamente, a pesquisa partiu de um estudo bibliográfico, tendo em vista desenvolver maior profundidade e discernimento teórico a respeito do assunto apresentado. Em continuidade, a pesquisa ainda pode ser caracterizada como qualitativa, ao momento em que se fez uso de um instrumento de coleta de dados elaborado por meio de questões abertas e fechadas, sendo aplicado aos colaboradores da estação da RGE da cidade de Palmeira das Missões/RS e tabulados com auxílio de uma planilha eletrônica do Excel.

Além de obedecer critérios de uma pesquisa descritiva, ao analisar e relatar informações decorrentes do ambiente de estudo a pesquisa contemplou uma análise documental a priori, do retrospecto histórico do cooperativismo de eletrificação rural, estatais e a privatização, considerando a normativa vigente. Ainda, o estudo obedece à características de um estudo de caso, pois busca analisar de maneira isolado o "objeto de estudo", tendo em vista uma análise em profundidade".
Por outro lado, o instrumento de coleta dos dados buscaram contemplar os tipos de ocorrências de problemas e serviços mais comuns na Estação, e posteriormente levantar informações mais relevantes. Quanto ao desenvolvimento do questionário, o mesmo foi desenvolvido com base na leitura e análise da Normativa 414/2010. Já referente à escolha dos funcionários para a realização da pesquisa buscando identificar se os respondentes possuíam conhecimento sobre a normativa que regulamenta e estabelece alguns princípios norteadores da prestação do serviço de distribuição de energia elétrica para os consumidores e por serem eles os que executam os serviços demandados.

Assim, no que tange o universo da população, o tipo de amostragem escolhido caracteriza-se por uma amostragem não probabilística, não intencional por conveniência. Deste modo, buscou-se aplicar o referente questionário dentro da unidade da RGE, conforme os colaboradores presentes. A totalidade de funcionários que aborda a unidade corresponde a 35 na Estação Avançada de serviço de campo (EA1) de Palmeira das Missões-RS. Desta forma, a pesquisa conseguiu contemplar nove técnicos, oito atendentes de campo (eletricistas de manutenção), e três funcionários do setor administrativo, sendo um total de 20 questionários respondidos.

Ainda, salienta-se que antes da aplicação do questionário, o instrumento de coleta dos dados foi testado para verificar quanto a dificuldades de interpretação dos respondentes. Desta maneira, após elaborado o questionário, inicialmente o questionário fora desenvolvido e avaliado por professores doutores e especialistas na área, que prontamente fizeram modificações e adaptações sobre as variáveis. Após este momento, o instrumento de coleta dos dados foi aplicado a uma pequena amostra de colaboradores da unidade da RGE, e assim, retornando com alguns ajustes a serem realizados antes da aplicação propriamente utilizada para dar início a aplicação da pesquisa.

Desta maneira, algumas variáveis apresentadas ao longo dos resultados da pesquisa, buscou contemplar as variáveis apresentadas no instrumento de coleta dos dados aplicado junto aos colaboradores da cooperativa: 
Quadro 01: Variáveis abordadas no instrumento de coleta dos dados

\begin{tabular}{|l|}
\hline \multicolumn{1}{|c|}{ INFORMAÇÕES PESSOAIS } \\
\hline 1) Tempo de Empresa: \\
\hline 2) Setor que trabalha: \\
\hline \multicolumn{1}{|c|}{ PROBLEMAS E SERVIÇOS: } \\
\hline 3) Escolaridade: \\
\hline 4) Tipo das ocorrências quanto a falha de distribuição de energia elétrica da RGE em Palmeira das Missões \\
\hline 5) Problemas podem ser considerados mais relevante na Estação da RGE em Palmeira das Missões \\
\hline 6) Fator precisa ser estudado e melhorado na prestação de serviços da RGE na região de Palmeira das Missões? \\
\hline $\begin{array}{l}\text { 7) Atendimento telefônico de qualidade, buscando satisfazer os consumidores com um atendimento de nível } \\
\text { elevado de clareza e eficiência? }\end{array}$ \\
\hline 8) Informações aos consumidores quanto as bandeiras tarifárias \\
\hline $\begin{array}{l}\text { 9) Central de tele-atendimento com estrutura física e de pessoal adequado, com o objetivo de centralizar o rece- } \\
\text { bimento de ligações telefônicas, distribuindo-as automaticamente aos atendentes. }\end{array}$ \\
\hline $\begin{array}{l}\text { 10) Realiza a revisão tarifária periódica conforme previstas nos contratos de concessão, levando em considera- } \\
\text { ção as alterações de custos de mercado e da concessionária. }\end{array}$ \\
\hline
\end{tabular}

Fonte: Constructo do autor segundo Normativa 414/2010.

Assim, conforme o quadro 01, foi possível identificar as variáveis contempladas ao longo do instrumento de coleta dos dados aplicados dentro da unidade da cooperativa RGE, localizada no município de Palmeira das Missões/RS.

\section{Análise dos resultados}

De acordo com a ilustração 01,13 dos entrevistados têm mais de 5 anos de empresa. Já 4 destes possuem de 2 a 5 anos e apenas 3 têm menos de um 1 de empresa. Percebe-se que a rotatividade de pessoal na empresa é baixa, podendo ser explicado pelo fato de os colaboradores serem motivados por meio de recompensas e benefícios, de acordo com o seu desempenho profissional.

Ilustração 1 - Tempo que os colaboradores têm de empresa

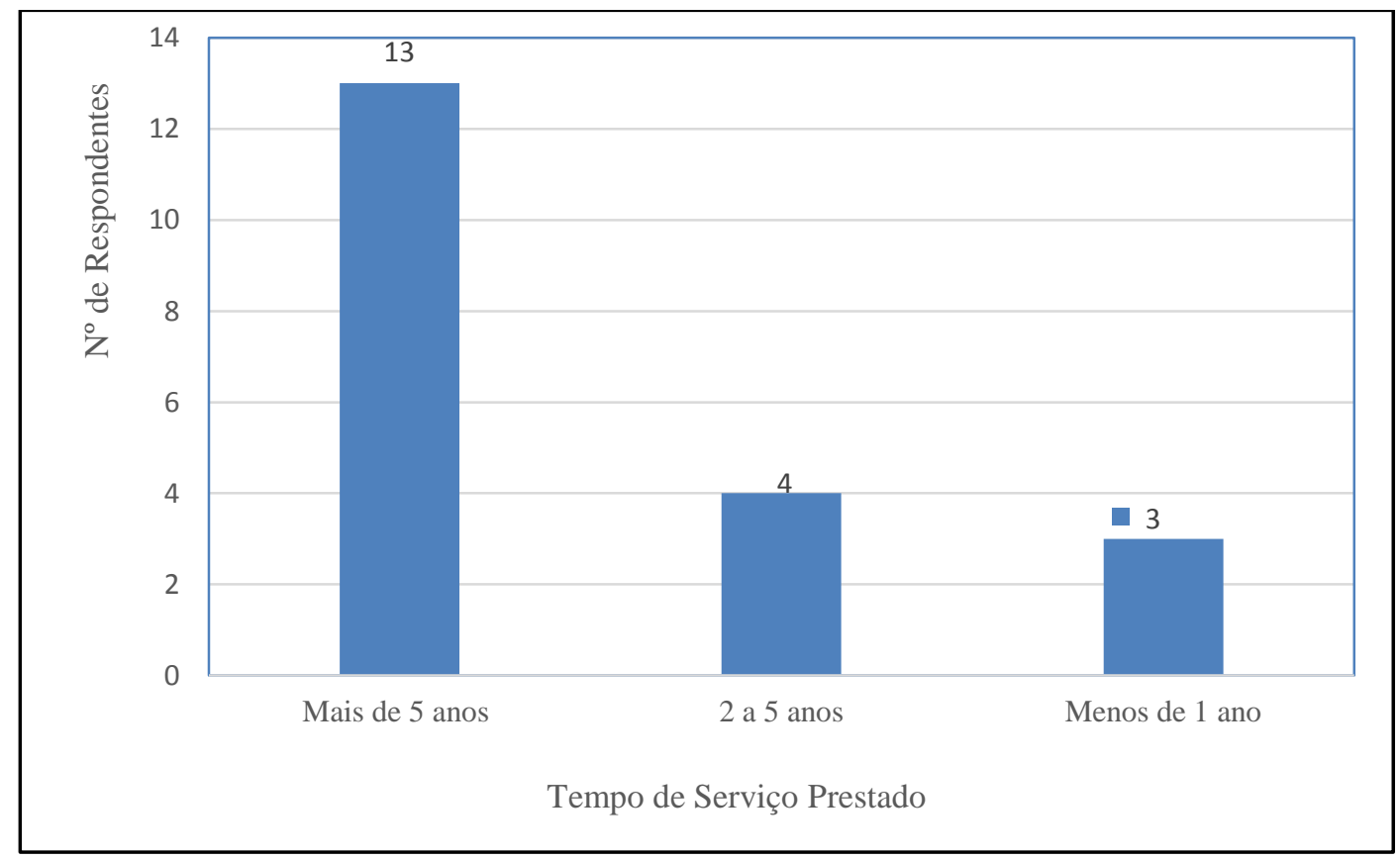

Fonte: Dados da Pesquisa 
Com relação à função exercida, destaca-se que dos técnicos, 8 são atendentes de campo (eletricistas de manutenção), e 3 trabalham no setor administrativo. Este número justifica-se, por tratar-se de uma empresa prestadora de serviço público de distribuição de energia, a qual precisa contar com um maior número de técnicos e eletricistas de manutenção para que possam suprir as demandas dos consumidores com eficiência.

O nível de escolaridade dos colaboradores ainda é baixo, pois conforme a pesquisa apenas um deles possui curso superior. Esse número é preocupante, já que na cidade de Palmeira das Missões existem muitas oportunidades de ingressar no ensino superior na modalidade particular e uma universidade federal, inclusive também na modalidade à distância, levando em consideração que muitos destes trabalham com sobreaviso no turno da noite e não podem frequentar um curso presencial.

A profissionalização e o plano de carreira são fatores importantes nesta empresa, pois a qualificação e a valorização do funcionário contribuem para a modernização na gestão da mesma. O plano de carreira serve para o desenvolvimento dos colaboradores e proporciona uma visão das possibilidades de crescimento dentro da organização.

Deste modo, o nível de escolaridade é contrário a afirmação, que através da Reforma do Estado Brasileiro, "implica em um elevado grau de profissionalização dos servidores públicos, orientado em processos utilizando estratégias de modernização" (FADUL, 2006, p.3).

$\mathrm{Na}$ ilustração 02, é possível visualizar os tipos de ocorrências que mais acontecem nas redes da estação.

Ilustração 02 - Tipos de Ocorrências que mais acontecem nas redes da Estação

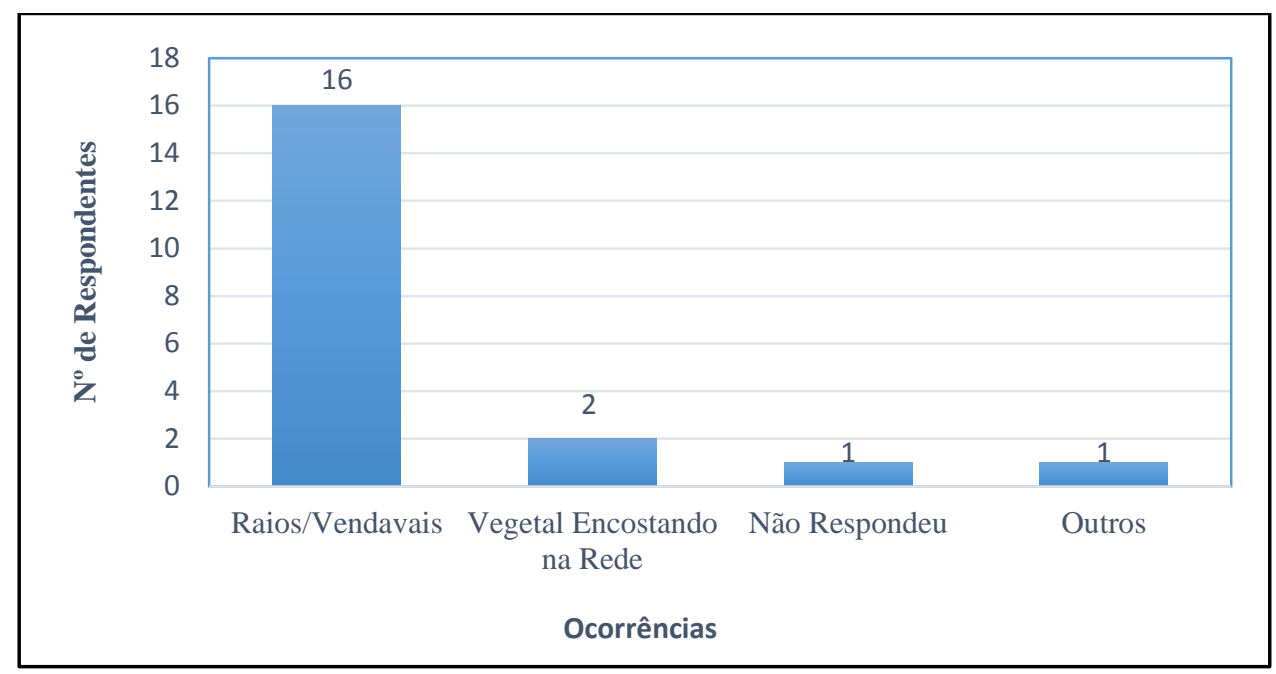

Fonte: Dados da Pesquisa

Como foi possível visualizar, na opinião de 16 respondentes os tipos de ocorrências que mais acontecem nas redes da RGE é provocado por fatores climáticos de raios e vendavais, entre esses respondentes, 2 trabalham no administrativo. Para outros 2, os vegetais encostando-se à rede é também outro tipo de ocorrência que acontece demasiadamente e já outros 2 colaboradores responderam que não sabem ou que existem outros fatores que acontecem as ocorrências.

O desempenho dos sistemas de distribuição de energia e a qualidade da distribuição desta são sus- cetíveis a variações climáticas, mais especificamente aos ventos, descargas elétricas e chuvas acima da média. No Brasil, esses tipos de ocorrências são muito comuns nas regiões sul e sudeste do país. A identificação dessas ocorrências e efeitos de variações climáticas é importante para o planejamento e elaboração de projetos, bem como a manutenção das redes. Portanto, estudos podem gerar informações de grande utilidade que poderão ser transformadas em ações preventivas contra esses fenômenos naturais (FARIAS; CORREIA, 2008). 
Ilustração 3 - Problemas considerados mais relevantes na prestação de serviços

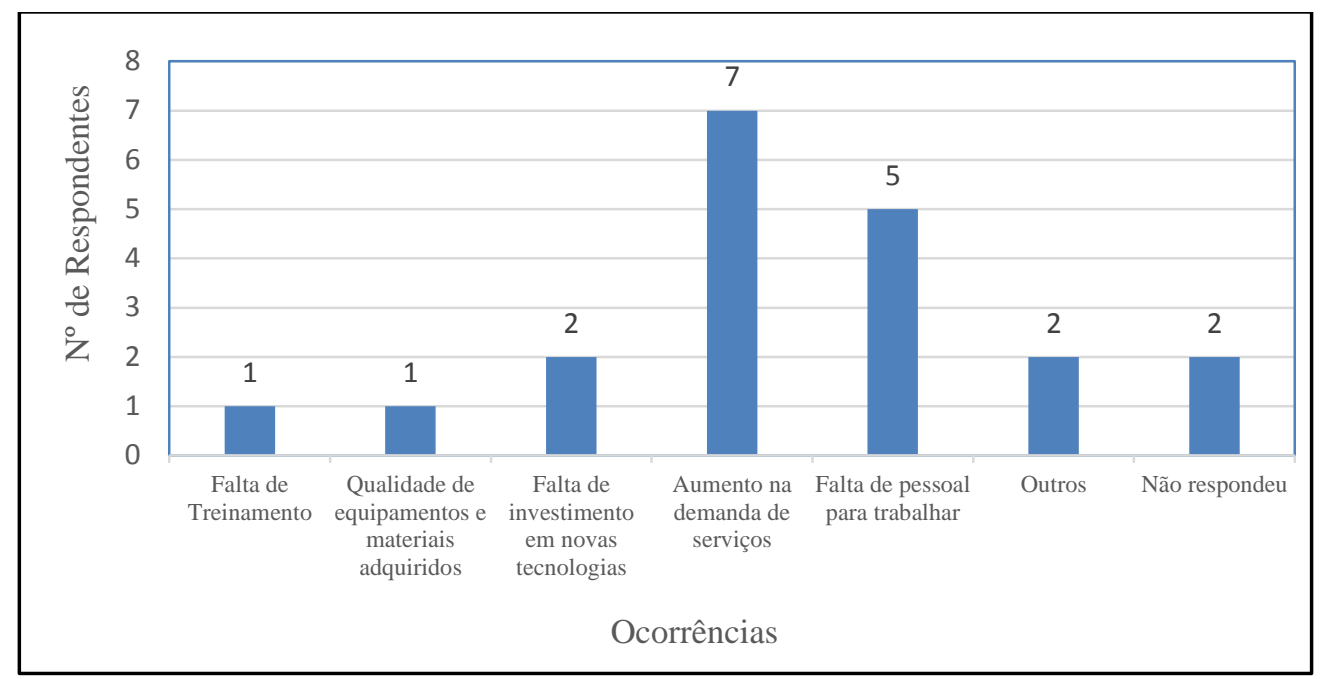

Fonte: Dados da Pesquisa

Na ilustração 03, verificam-se os problemas considerados mais relevantes na prestação de serviços. Para 5 dos respondentes distribuídos entre o setor técnico e administrativo a falta de pessoal para trabalhar nessa atividade de distribuição de energia é significativa. Ressalta-se que existe mão-de-obra especializada para o desempenho da função requerida, considerando que a região possui diversos cursos técnicos na área, sendo que a própria empresa disponibiliza de auxílio financeiro para a realização dos mesmos. Entretanto, nem todos os técnicos da área se submetem a assumir tal responsabilidade, considerando as exigências que a função requer, como por exemplo, ficar de sobreaviso à noite $\mathrm{e}$ fazer plantões nos finais de semana.

Conforme mostra a ilustração 03, ainda no que tange aos problemas considerados mais relevantes na prestação de serviços, 2 respondentes que traba- lham nos setores de atendimento de campo e técnico colocam a falta de investimentos como uma dificuldade, em que 1 alega ser um obstáculo à baixa qualidade dos materiais adquiridos e outro afirma que a falta de treinamento também gera problemas. Corroborando com este resultado, Correia et. al (2006), diz que nos anos 90 ocorreu a contestação de que o Estado não tinha mais capacidade de investir na área de energia elétrica sem comprometer sua própria eficácia na atuação. Em função disso, surgiram as privatizações, ou seja, foi transferido para a esfera privada o compromisso de investir em tecnologia, compra de materiais de qualidade, treinamento para os funcionários e infraestrutura no ramo de distribuição de energia elétrica.

No que tange aos fatores que precisam ser melhorados na prestação de serviços, estes podem ser vistos na Ilustração 04.

Ilustração 4 - Fatores que precisam ser melhorados na prestação de serviços

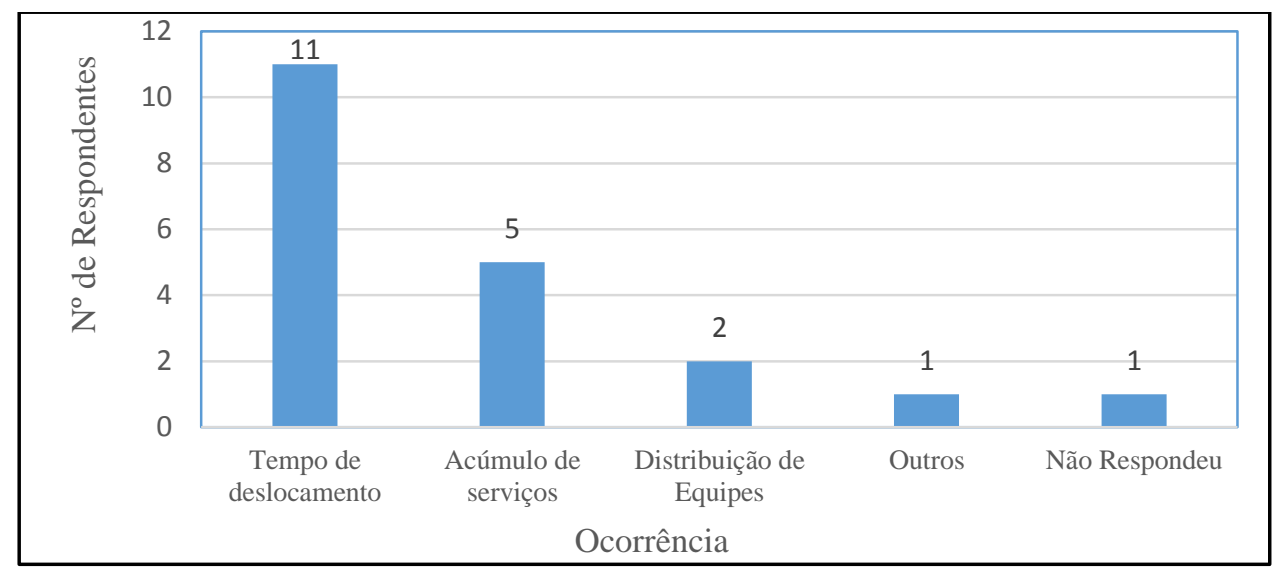

Fonte: Dados da Pesquisa 
Conforme contatado na Ilustração 04, um número expressivo de 11 colaboradores que trabalham no atendimento de campo e técnico afirmaram que o fator que precisa ser estudado para melhorar a prestação de serviço é o tempo de deslocamento pela equipe. Isso pode estar relacionado ao fato de que a estação ainda não possui um COD em Palmeira das Missões. Então, as ordens de serviços para a equipe ir a campo são autorizadas pela sede da empresa na cidade de Caxias do Sul. Outro ponto relevante são as longas distâncias que precisam ser percorridas para chegar até os municípios vizinhos.

As interrupções de fornecimento de caráter sistêmico nos serviços ou atividades essenciais precisam ser atendidas com brevidade já que a falta de energia elétrica pode colocar em perigo a sobrevivência, saúde e segurança dos cidadãos. O tempo de deslocamento implicado no atendimento dessas ocorrências que podem ser demandadas por unidades hospitalares (centros de hemodiálises e armazenamento de sangue, instituto médico legal, distribuição de vacinas e soros antídotos), captação e tratamento de esgoto e lixo, unidade de abastecimento de água, unidades de segurança pública (corpo de bombeiros e polícias), unidades de transporte coletivo, unidade de serviço público de telecomunicações, possibilitam uma enormidade de sérios problemas.

Para um número de 5 colaboradores o acúmulo de serviços é um fator que precisa ser avaliado. Associa-se a isso a falta de pessoal para trabalhar neste serviço na região e o aumento na demanda de serviços. Parte do acúmulo de serviço se dá em virtude do tempo de deslocamento, pois a demora em atender uma ocorrência acaba atrasando o atendimento de outra. Neste ponto é possível colocar em evidência que a privatizada atende 21 municípios com apenas 35 funcionários. Então, se torna difícil para a gestão planejar os serviços com um número muito pequeno de funcionários para atender uma área muito abrangente.

No que tange a qualidade no atendimento telefônico considerada pelos pesquisados, esta pode ser vista na Ilustração 05.

Ilustração 05 - Qualidade no atendimento telefônico

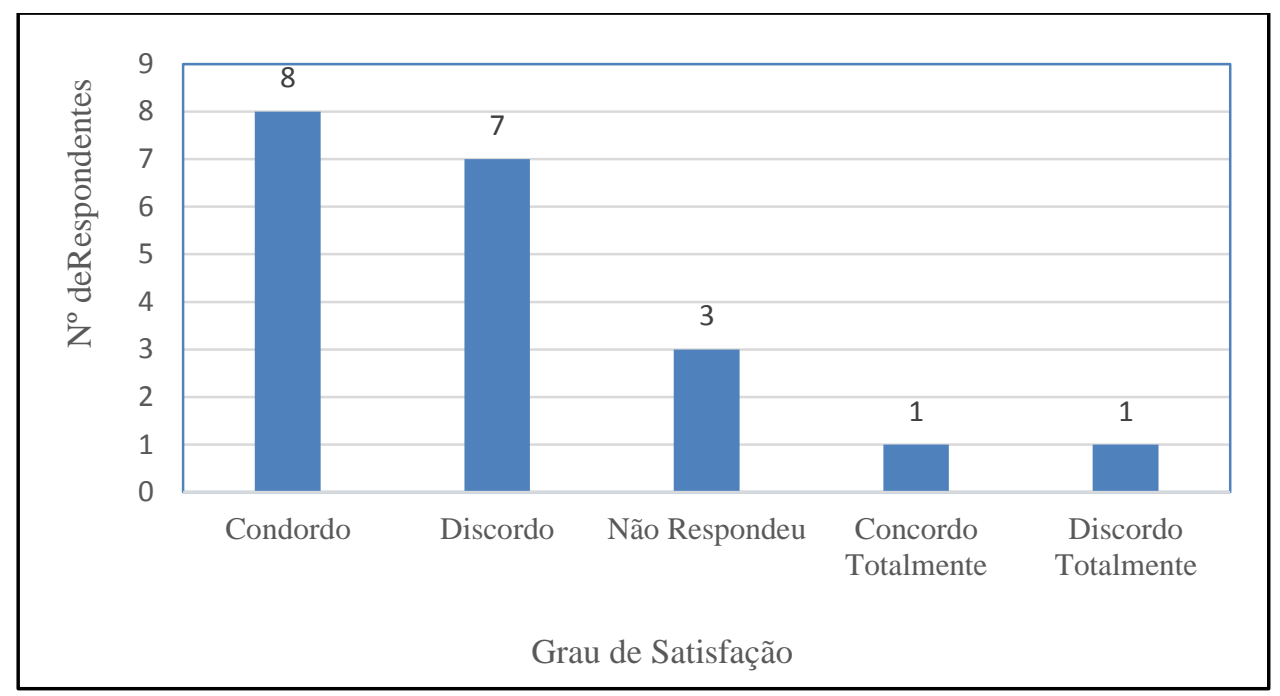

Fonte: Dados da Pesquisa

Ao observar a ilustração 05 , percebe-se que 14 respondentes concordam que o atendimento telefônico é de qualidade, 5 deles, especificamente do setor técnico, discordam que a Estação da RGE tem um atendimento telefônico de qualidade conforme determina a Normativa 414 e apenas 1 discorda totalmente.
Ressalta-se nesse contexto, que atender com qualidade e cortesia, seja presencialmente ou por atendimento telefônico, é uma tarefa difícil e que necessita de treinamento, investimento e desenvolvimento para uma melhoria na qualidade da prestação do serviço. A partir disso, a organização enfrenta algumas dificuldades para treinar os funcionários onde uma delas pode ser a rejeição destes em parti- 
cipar de treinamentos e desenvolvimento (COSTA; NAKATA; CALSANI, 2013).

Por outro lado, esse ponto não está em total conformidade com a Normativa, o Call Center, que está localizado na cidade de Indaiatuba em São Paulo e as solicitações ou reclamações dos clientes são atendidas por lá e repassadas à sede em Caxias do Sul que autoriza as execuções de serviços na região em Palmeira das Missões. Também, a Estação em Palmeira das Missões possui apenas um telefone fixo na recepção para informações e as demais ligações são atendidas por celulares.

A Estação em Palmeira das Missões possui apenas um telefone fixo na recepção para informações e as demais ligações são atendidas por celulares.
Muito embora o governo tenha realizado privatizações em 1990 no setor elétrico brasileiro, grande parte dos recursos alocados para prestação do serviço público de distribuição de energia e infraestrutura foi investido pelo Estado. Sendo assim, a necessidade de um planejamento para desenvolver ações de melhorias na prestação de um serviço de qualidade para a população e preços adequados coloca em evidência a fragilidade nas fiscalizações por parte do órgão regulamentador (GOMES, 2012).

A resposta sobre o questionamento se os consumidores são informados sobre as bandeiras tarifárias pode ser vista na ilustração 06 .

Ilustração 6 - Informações aos consumidores sobre bandeiras tarifárias

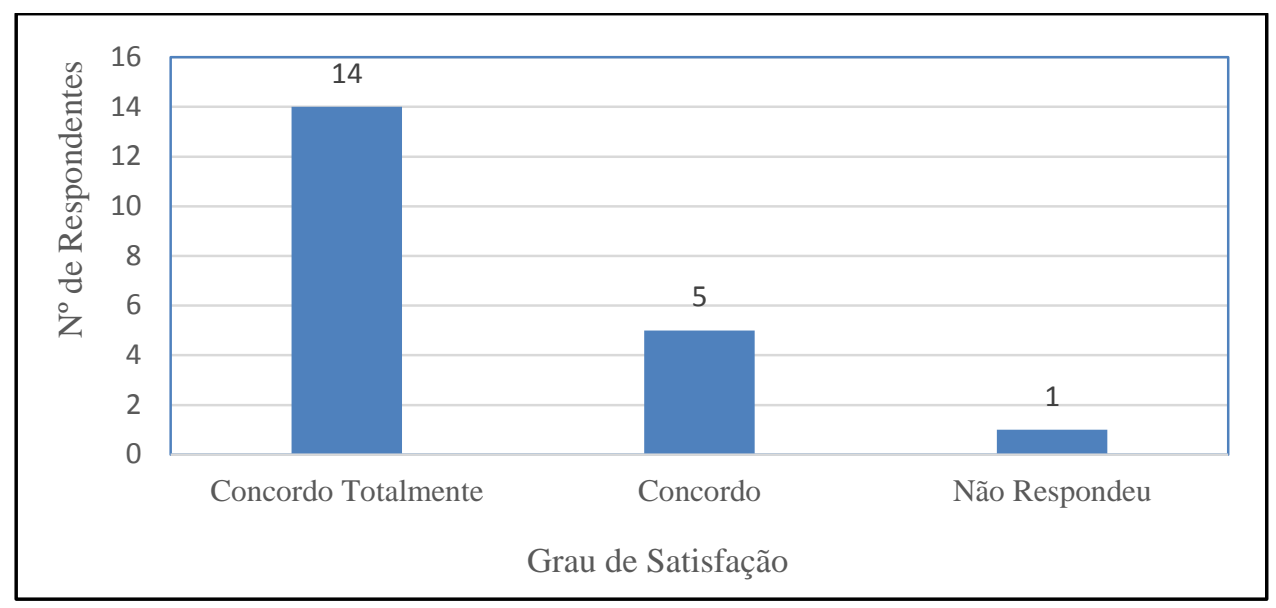

Fonte: Dados da Pesquisa

Referente ao exposto na ilustração 06 , percebese que 14 dos colaboradores concordam que os consumidores são informados sobre as bandeiras tarifárias de consumo e 5 concordam totalmente, destes respondentes 3 trabalham na área administrativa e 2 são técnicos.

As bandeiras tarifárias influenciam no valor pago mensalmente pelo consumo em determinada unidade consumidora. Elas são informadas no boleto de cobrança de energia com o intuito que o consumidor saiba discriminadamente pelo que está pagando (consumo da unidade, impostos, iluminação pública e valor da bandeira tarifária).

Em função disso o grande beneficiário dos ajustes tarifários foi o segmento privatizado da indústria elétrica. Porém, boa parte dos aumentos das tarifas de energia decorre de encargos, impostos e taxas instituídas por decisão do governo (EPE, 2015).

Por outro lado, os dados oficiais do Balanço Energético 2014 inferem que do total da demanda do setor energético brasileiro, aproximadamente $25 \%$ dos serviços são destinados ao consumo domiciliar contra $50 \%$ incorporado ao consumo industrial. Entretanto, mesmo que haja a quantificação de energia elétrica distribuída em cada setor, é possível presumir e evidenciar que o governo não possui uma boa política de transparência frente à população referente à sua forma de gerenciar o Estado quanto a sua malha energética (AXA, 2015).

Assim sendo, ao aplicar a tributação sobre a prestação de serviço a população brasileira, o Estado não atua de maneira transparente aos acréscimos voltados a conta de energia elétrica, atribuindo sua 
conduta, através da imposição de decisões governamentais, negligenciando a opinião e a participação popular.

Destaca-se ainda que a partir de janeiro de 2015, a população brasileira sofreu um acréscimo relevante sobre a tarifa mensal cobrada pelo serviço público prestado de energia elétrica, denominado como cobrança tarifária "bandeira vermelha" atribuindose um aumento de $\mathrm{R} \$ 3,00$ a cada $100 \mathrm{kwh}$ consumido. Portanto, tal medida veio a ser imposta pelo governo em resposta aos gastos governamentais exorbitantes que provocaram a crise econômica atual (AXA, 2015).

\section{Considerações finais}

Levando em consideração que o objetivo desse estudo que caracteriza-se por identificar os problemas mais comuns na prestação do serviço de distribuição de energia elétrica, bem como ressaltar os fatores que precisam ser melhorados para otimizar a qualidade do serviço prestado pela cooperativa Rio Grande Energia S.A (RGE), unidade de Palmeira das Missões, verificou-se que os tipos de ocorrências mais comuns na área de abrangência são provocados por raios e vendavais e os problemas mais relevantes é decorrente do aumento na demanda de serviços e a falta de pessoal para trabalhar.

Por outro lado, após analisadas as informações coletadas e interpretada as variáveis, no que tange aos resultados, sugere-se à empresa privatizada em questão, que desenvolva um estudo referente ao tempo de deslocamento de seus funcionários para o atendimento das ocorrências, visto que este representa o principal fator a ser melhorado na visão $55 \%$ dos entrevistados.

Quanto aos problemas ocasionados por fatores climáticos, recomenda-se que a empresa realize um plano de ação especialmente para as épocas climáticas complicadas do ano, onde podem ocorrer fenômenos como raios e vendavais já que nesta região as quatro estações do ano são bem definidas. Se possível, que recorra ao auxílio de informações meteorológicas precisas sobre as tendências climáticas nas regiões de sua abrangência e, futuramente poderá contratar um profissional desta área para trabalhar na Estação.

Em vista do aumento da demanda, o acúmulo de serviços e a falta de pessoal para trabalhar são necessários à contratação de mais mão de obra, porém inicialmente é preciso que sejam reavaliadas as políticas de horários, salários e benefícios, bem como as questões de segurança do trabalhador para que mais pessoas se interessem por esse trabalho.

Tendo em vista o aumento da demanda desse serviço público de forma gradativa, sugere-se que realize a implantação de um Centro da Operação e da Distribuição, onde os técnicos poderiam visualizar as ocorrências dentro da estação para orientar os eletricistas de manutenção, além de uma Central de Tele Atendimento com pessoal e estrutura adequados.

Também para melhorar o atendimento telefônico os gestores precisam rever a questão da qualidade, de forma a facilitar para os consumidores o acesso ao atendimento através de uma linha direta, no intuito de agilizar as solicitações de serviços. Salienta-se também, a importância em treinar o atendente para que este realize a função com prestatividade e cortesia, garantindo assim, a satisfação dos consumidores.

A privatizada está focada apenas em distribuir a energia até os pontos de consumo, ou seja, seu modelo de gestão é focado no produto. Sabendo que a empresa é responsável pela distribuição de um serviço público essencial a toda a população, seu enfoque de gestão precisa se expandir, visando à melhoria contínua de todo o seu processo, desde a sua distribuição, manutenção e atendimento das demandas, objetivando prestar um serviço de qualidade para os consumidores.

Outro fator relevante que precisa ser avaliado visando melhorar a qualidade da prestação do serviço de fornecimento de energia elétrica é o tempo de deslocamento e o acúmulo de serviços. Considerado como uma limitação da Estação, a falta de infraestrutura adequada com uma central de tele atendimento destaca-se. Com a implantação de uma, será possível melhorar o contato telefônico com os consumidores que consequentemente agilizará as ordens de serviços.

Ressalta-se ainda que o gestor da Estação precisa gerenciar os desafios da Normativa e suas definições legais, acompanhando as evoluções do mercado e o aumento da demanda de prestação desse serviço essencial. Além disso, é necessário planejar as ações e controlar o acúmulo de serviços baseado na mão-de-obra disponível.

As empresas privatizadas de distribuição de energia elétrica requerem uma retomada de investi- 
mentos e uma adoção de ações estratégicas para suportar as necessidades relevantes nas operações desse tipo de organização. Essas ações sinalizam ser pertinente a adoção de níveis de excelência na gestão das operações e serviços e se necessário terceirizar alguns deles. Essa estratégia visa manter a empresa equilibrada diante das regulamentações do setor elétrico e a necessidade de atender o crescimento do mercado (CORREA, 2008).

O grau de controle do Estado na regulação do setor elétrico brasileiro influencia diretamente no controle da política de preços, nas metas, qualidades de serviços e atendimento (SERVA, 2003). Diante disso, é importante que a gestão da empresa se atualize com estudos e pesquisas, pois até o momento, na Estação nenhuma pesquisa havia sido realizada com os funcionários para levantamento de dados sobre os problemas e serviços mais comuns a fim de melhorar a prestação desse serviço.

A partir desse estudo, sugere-se que sejam realizadas pesquisas futuras utilizando-se de outros métodos de coletas de dados, os quais possibilitem a participação dos consumidores que utilizam o serviço público prestado pela RGE na região de Palmeira das Missões. Uma possibilidade é implantar e desenvolver a estratégia de pesquisa mensal com o consumidor.

\section{Referências}

ANEEL - Agência Nacional de Energia Elétrica. Disponível em < http://www.aneel.gov.br/> Acesso em 10 de Julho de 2015.

AXA. Articulação Xingú Araguaia/ORG. Disponível em: < http://www.axa.org.br/2015/03/a-crisedo-setor-energetico-brasileiro-e-os-apagoesdiarios-do-araguaia/ $>$. Acesso em 24 de julho de 2015.

BANCO CENTRAL DO BRASIL. Revista da Procuradoria Geral - do Banco Central. Ed. Banco central do Brasil. Brasília. Vol.7, 2013.

BRASIL. Agencia Nacional de Energia Elétrica. Resolução Normativa no 414/2010. ANEEL, 2010.

COSTA, Cintia Uehara da. NAKATA, Yuriko Uehara. CALSANI, Juliana Rissi da Silveira. Qua- lidade no atendimento: a influência do bom atendimento para conquistar os clientes. In: Revista Científica Eletrônica UNISEB, Ribeirão Preto, v.1, n.1, p.54-65, janeiro a junho de 2013.

CORREIA, Tiago B., et al. Trajetória das Reformas Institucionais da Indústria Elétrica Brasileira e Novas Perspectivas de Mercado. Revista Economia. Setembro/Dezembro de 2006.

CRELUZ - Cooperativa de Geração e Distribuição de Energia.

Disponível em: < http://www.creluz.com.br > Acesso em julho de 2015.

DI PIETRO, Maria Sylvia Zanella. Direito Administrativo. Atividades e Atos Administrativos. $4^{\mathrm{a}}$ ed. São Paulo: Atlas, 2002, p. 366.

EPE. EMPRESA DE PESQUISA ENERGÉTICA. Disponível em <http://www.epe.gov.br> Acesso em 07 de julho de 2015.

FADUL, Élvia Maria Cavalcanti. Regulação de serviços públicos num contexto de reforma do Estado e privatização no Brasil: impactos no setor de energia elétrica. Revista Gestão e Planejamento. $N^{\circ} 10$. Salvador. Julho a Dezembro de 2006.

FARIAS Wendell Rodinelli Gomes e CORREIA, Magaly de Fátima. Descargas Atmosféricas e Interrupções de Energia Elétrica na área da

CHESF; Relação com variáveis atmosféricas em anos de El Niño e La Ninã. In: Revista Brasileira de Meteorologia, v.23, n.3, p. 270-281, 2008.

FARINA, Elizabeth Maria Mercier Querido. Desregulamentação e o controle do abuso do poder econômico: teoria e prática. Revista de Economia Política, vol. 14, no 3, (55) julho - setembro de 1994.

FECOERGS - Federação das Cooperativas de Eletrificação Rural do Estado do Rio Grande do Sul. Disponível em <http://www.fecoergs.com.br> Acesso em julho de 2015.

FIGUEIREDO, Breno Pinto. Estratégias Competitivas e Modelos de Gestão Empresarialno Setor Elétrico Brasileiro. Monografia apresentada ao 
Instituto de Economia Industrial da Universidade Federal do Rio de Janeiro para obtenção do título de MBA em Energia Elétrica,1999. Disponível em

$<$ http://www.eletrobras.com/elb/services/Docum entManage-

ment/FileDownload.EZTSvc.asp\%3FDocumentI D\%3D\%257B8ED910B > Acesso em 10 de julho de 2015.

GIL, Antônio Carlos. Observação. Métodos e Téc-

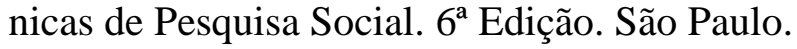
Ed. Atlas. 2008. p.121 - 135.

GOMES, Marcel. Onde está o investimento privado? In: Instituto de Pesquisa Econômica Privadas. Desafios do Desenvolvimento. 2012. Disponível em $<$ http://www.ipea.gov.br/desafios/index. php?option=com_content $\&$ view $=$ article $\&$ id $=282$ 9: catid=28\&Itemid=23. $>$ Acesso em 11 de julho de 2015.

GUIMARAES, Tomás de Aquino e SILVA, Eduardo Ramos Ferreira da., Autonomia e flexibilidade na gestão da regulação dos setores de energia elétrica e de telecomunicações no Brasil. In: V Congresso Internacional Del CLAD sobre La Reforma Del Estado y de La Administración Pública, Santo Domingo, República Dominicana, 24 - 27 Outubro de 2000.

LANDI, Mônica. Estado, regulação econômica e serviços públicos: uma abordagem para o setor elétrico brasileiro. In: XII Congresso Internacional Del CLAD sobre La Reforma Del Estado y de La Administración Pública, Santo Domingo/República Dominicana, 30 de outubro a 2 de novembro de. 2007.

MACHADO, Mauro Cesar Noronha. Fiscalização das distribuidoras de energia elétrica com a aplicação da ferramenta de gestão da qualidade Ciclo PDCA. 2014. Dissertação de Mestrado em Ciências em Engenharia Elétrica apresentado a Universidade Federal de Itajubá para obtenção do título de Mestre em Ciências em Nome do Programa de Pós-Graduação em Engenharia Elétrica. Itajubá/MG, 2014.
MALMEGRIN, Maria Leonídia. Gestão Operacional. Universidade Federal de Santa Catarina. UFSC. CAPES. 2010.

MIRANDA, Rubens Augusto de e AMARAL, Hudson Fernandes. Governança Corporativa e Gestão Socialmente Responsável em Empresas Estatais. Revista de Administração Pública. Rio de Janeiro 45(4) p. 1069-94, julho a agosto de 2011.

MONTAVÃO, Edmundo e MENDES, Marcos. O que é "subsídio cruzado" e como ele afeta sua conta de luz? In: Brasil Economia e Governo/ORG. 2012. Disponível em < http://www.brasil-economiagoverno.org.br/2012/02/12/o-que-e-subsidiocruzado-e-como-ele-afeta-a-sua-conta-de-luz/> Acesso em 15 de julho de 2015.

NILSSON, Gunnar. A suspensão do fornecimento do serviço essencial de energia elétrica ao usuário inadimplente - análise sob a perspectiva constitucional e consumerista. Revista Eletrônica da PUCRS. Direito \& Justiça.

v. 38, n. 2, p. 141-155, julho - dezembro. 2012. Disponível em http://revistaseletronicas.pucrs.br/ojs/index. php/fadir/article/viewFile/12541/8407 Acesso em 15 de julho de 2015.

PELEGRINI, M. A.; et al. O processo de regularização de cooperativas de eletrificação rural no estado de São Paulo. In: Encontro de Energia Rural. 2003. Disponível em <http://www.proceedings.scielo.br/scielo. php?pid=MSC0000000022000000100042\&scrip $\mathrm{t}=$ sci_arttext\&tlng=pt $>$ Acesso em julho de 2015.

PRADO, João Alderi. CRERAL - uma experiência de cooperativa na eletrificação rural e a nova legislação para as cooperativas. In: Encontro de Energia do Meio Rural. 2002. Disponível em $<$ http://www.proceedings.scielo.br/scielo. php?pid=MSC0000000022002000100041\&scrip $\mathrm{t}=$ sci_arttext $>$ Acesso em 08 de julho de 2015

QUEIROZ, Leonardo Mendonça Oliveira de. Estimação e Análise das Perdas Técnicas na Distribuição de Energia Elétrica. Tese de Doutorado 
apresentada à Faculdade de Engenharia Elétrica e de Computação como parte dos requisitos para obtenção do título de Doutor em Engenharia Elétrica. Campinas, 2010. Disponível em < http://www.aneel.gov.br/biblioteca/trabalhos/abe rtura. cfm> Acesso em 29 de março de 2015.

SERVA, Maurício. Análise de empresas privatizadas: $\mathrm{O}$ desafio da multidimensionalidade. In: Civitas - Revista de Ciências Sociais. v. 3, $\mathrm{n}^{\circ}$ 2, julho a dezembro de. 2003, p. 349-373. Disponível em < http://revistaseletronicas.pucrs.br/ojs/index. php/civitas/article/view/125> Acesso em julho de 2015.

SILVA, Mariana Batista da. Mecanismos de participação e atuação de grupos de interesse no processo regulatório brasileiro: o caso da Agência Nacional de Energia Elétrica (Aneel). Universidade Federal de Pernambuco. Revista de Administração. Pública. Rio de Janeiro 46(4) p. 96992, julho a agosto de 2012.

SILVA, Valeria Sales Miguel da. Serviço público de energia elétrica, na ótica do direito do consumidor: um estudo crítico sobre a reparação civil em caso de ineficácia na prestação do serviço. In: Âmbito Jurídico, Rio Grande, XVII, n. 123, abril de 2014. Disponível em:

$<$ http://www.ambitojuridico.com.br/site/?n_link=revista_artigos_leitura\&a rtigo_id=14622>. Acesso em 15 de julho de 2015.

ZILBER, Moises Ari. LEX, Sergio. ADES, Cely. As privatizações e o novo modelo do setor Elétrico Brasileiro: O impacto sobre o atendimento das necessidades do consumidor. In: Gestão \& Regionalidade. IMES Universidade. Ano XXI, $n^{\circ} 61$, janeiro a junho de 2005. Disponível em < http://seer.uscs.edu.br/index. php/revista_gestao/article/download/44/4 > Acesso em 10 de julho de 2015. 
